\title{
Characterization of young kerogen in a lacustrine sediment by alkaline potassium permanganate oxidation
}

\author{
TSUTOMU MachiHaRa and Ryoshi IshiwataRI \\ Department of Chemistry, Faculty of Science, Tokyo Metropolitan University, \\ Fukazawa, Setagaya-ku, Tokyo 158, Japan
}

(Received September 29, 1980; Accepted December 12, 1980)

\begin{abstract}
The insoluble organic matter (young kerogen) in a surface sediment from Lake Haruna was subjected to alkaline permanganate oxidation. The young kerogen was easily degraded under the mild condition and relatively large amounts of $\mathrm{CO}_{2}$ and acid-insoluble material (alkali-soluble but precipitated in acidsolution) were generated at the early stages of the oxidation. The major oxidation products determined by GC-MS were aliphatic $\alpha$, $\omega$-dicarboxylic acids $\left(\mathrm{C}_{5}-\mathrm{C}_{16}\right)$. Benzene carboxylic acids (mono, di and tri) and aliphatic monocarboxylic acids $\left(\mathrm{C}_{8}-\mathrm{C}_{18}\right)$ were also detected in minor amounts. The yield of polymethylene chains $\left(\mathrm{C}_{5} \cdot \mathrm{C}_{18}\right)$ was $1.6 \%$ of the original kerogen. A hypothetical structure of the young kerogen was deduced from results obtained.
\end{abstract}

\section{INTRODUCTION}

A study of the chemical structure of kerogen is one of the fascinating problems in organic geochemistry, because an important role in the genesis of petroleum has been pointed out and its role in geochemical processes has been a subject of study. Therefore, many works have been devoted to elucidate the chemical structure of kerogens by chemical oxidation (BURLINGAME and SIMONEIT, 1968, 1969; BURLINGAME et al., 1969; DJURICIC et al., 1971, 1972; Simoneit and BurlingaMe, 1973, 1974; VITOROVIC et al., 1974; Young and YEN, 1977).

Organic materials similar to fossil kerogen are also present in recent sediments. HOER ING (1973) degraded kerogen from marine sediment with $\mathrm{K}_{2} \mathrm{Cr}_{2} \mathrm{O}_{7}$ and obtained monocarboxylic acids $\left(\mathrm{C}_{2}-\mathrm{C}_{10}\right)$ and $\alpha, \omega$-dicarboxylic acids $\left(\mathrm{C}_{3}\right.$ $\mathrm{C}_{6}$ ) as the major products. PHILP and CALviN (1977) and PHILP et al. (1978) performed oxidation $\left(\mathrm{CrO}_{3}\right.$ and $\left.\mathrm{KMnO}_{4}\right)$ studies on kerogens from algal mat and ooze. The main oxidation products were monocarboxylic $\left(\mathrm{C}_{10}-\mathrm{C}_{31}\right)$ and $\alpha, \omega$-dicarboxylic $\left(\mathrm{C}_{6}-\mathrm{C}_{16}\right)$ acids. They concluded that the basic framework of this kerogen consists of cross-linked polymethylene chains which on oxidation give rise to dicarboxylic acids. However, in those studies, no detailed studies have been undertaken on the degradation process of the young kerogens by the oxidizing reagents. A study to establish the oxidation condition is needed to obtain precise information on the chemical structure of a young kerogen.

In the present study, we have carried out permanganate oxidation on young kerogen from a lacustrine sediment (Lake Haruna), and examined its behavior toward oxidizing reagent and analyzed its degradation products, as the first step, to elucidate its chemical structure.

\section{EXPERIMENTAL}

\section{Sampling}

The sediment sample was taken from the deepest part of Lake Haruna, which is a representative mesotrophic lake in Japan (altitude $1,084 \mathrm{~m}$, area $1.23 \mathrm{~km}^{2}$, maximum depth $13.0 \mathrm{~m}$, volume $0.01 \mathrm{~km}^{3}$ ). The main source of organic materials in the sediment is considered to be phytoplankton populations (IsHIWATARI $e t$ al., 1980). 


\section{Isolation of kerogen}

The sediment sample was treated with $46 \%$ $\mathrm{HF} / 6 \mathrm{~N} \mathrm{HCl}(1: 1)$ at $60-70^{\circ} \mathrm{C}$ to decompose inorganic materials after removing lipid material by a Soxhlet extraction with benzene/methanol (6:4) for $70 \mathrm{hr}$. Humic acid was extracted from the residue by stirring with $0.5 \mathrm{~N} \mathrm{NaOH}$ solution. The kerogen obtained was then refluxed with $6 \mathrm{~N} \mathrm{HCl}$ for $20 \mathrm{hr}$ to diminish inorganic materials and to remove hydrolysable non-humic organic matter (such as amino acids and carbohydrates) as much as possible (RIFfald and Schnitzer, 1973). The resulting kerogen was washed thoroughly with distilled water and freeze-dried. Here, the kerogen before acid-hydrolysis was named "non-hydrolyzed kerogen: kerogen (Nh)"; and the kerogen after acid-hydrolysis was named "hydrolyzed kerogen: kerogen $(\mathrm{H})$ ".

\section{Permanganate oxidation}

The behavior of the Haruna kerogen toward $\mathrm{KMnO}_{4}$ was studied by three types of experiments. Experiment (1) was designed to test the stabilily of the kerogen toward $\mathrm{KMnO}_{4}$. Kerogen (Nh) was reacted with a sufficient amount of $\mathrm{KMnO}_{4}$ and the generation of $\mathrm{CO}_{2}$ and alkali-soluble products was examined. Experiments (2) and (3) were intended to see the degradation process of the kerogen in more details. In these experiments, $\operatorname{kerogen}(\mathrm{H})$ was used instead of kerogen (Nh), because the former is considered to be less contaminated with non-humic organic matter. In experiment (2), a certain amount of $\mathrm{KMnO}_{4}$ was added successively to the alkaline solution containing kerogen $(\mathrm{H})$, and after the reaction, the amounts of $\mathrm{CO}_{2}$, acid-soluble material (alkali-soluble and acidsoluble) and acid-insoluble material were examined. In Experiment (3), kerogen (H) was degraded by the stepwise oxidation and the degradation products were analyzed by GC and GC-MS.

Experiment (1): The kerogen (Nh) sample $(120 \mathrm{mg})$ was mixed with $40 \mathrm{ml}$ of $3 \% \mathrm{KMnO}_{4}-$ $1 \% \mathrm{KOH}$ aqueous solution in a silicon-stoppered $50 \mathrm{ml}$ flask and allowed to react at $60^{\circ} \mathrm{C}$ with stirring. At appropriate intervals ( $5 \mathrm{~min}-4 \mathrm{hr}$ ), an aliquot of the reaction mixture was taken out for the determination of dissolved organic carbon and carbon dioxide.

For the analysis of dissolved organic carbon (DOC), $1.0 \mathrm{ml}$ of the reaction mixture was filtered through a Whatman GF/F filter after reduction of the permanganate by sodium bisulfite. Organic carbon in the filtrate was determined by the method of MENzel and VACCARo (1964). Glucose was used as a standard for the carbon analysis.

Carbon dioxide in the solution was analyzed as follows: one hundred $\mu 1$ of the solution was taken out from the reaction mixture and injected into a $10 \mathrm{ml}$ glass ampoule with silicon stopper containing $3 \mathrm{ml}$ of $0.5 \% \mathrm{SnCl}_{2}$ in $0.1 \mathrm{~N} \mathrm{H}_{2} \mathrm{SO}_{4}$ solution to reduce the excess permanganate and manganese dioxide. The carbon dioxide generated was measured by the procedure similar to that for the analysis of organic carbon (MENzEL and VACCARo, 1964). $\mathrm{K}_{2} \mathrm{CO}_{3}$ solution was used as a standard for $\mathrm{CO}_{2}$ analysis. The error in the $\mathrm{CO}_{2}$ analysis was within $5 \%$.

Experiment (2): The kerogen $(\mathrm{H})$ sample (100mg) was oxidized with $20 \mathrm{ml}$ of $0.5 \%$ $\mathrm{KMnO}_{4}-1 \% \mathrm{KOH}$ solution in a $50 \mathrm{ml}$ flask at $60^{\circ} \mathrm{C}$ with stirring. At the end of the oxidation (marked by the disappearance of the purple color of the solution), an aliquot of the reaction mixture was taken out and measured for $\mathrm{CO}_{2}$ generated and DOC in alkaline solution after removing the unreacted kerogen by filtration. Then, a portion of the filtered solution was acidified by $\mathrm{HCl}$ to $\mathrm{pH} \sim 1$ and filtered to remove acid-insoluble material. The filtrate was subjected to the analysis of organic carbon.

The 2 nd oxidation was done by adding 100 mg $\mathrm{KMnO}_{4}$ (ca. $0.5 \%$ ) into the flask and the procedure mentioned above was repeated. At the end of the fifth oxidation, the mixture was filtered through a GF/F filter and organic carbon of the residue was measured.

Experiment (3): $1.00 \mathrm{~g}$ of kerogen $(\mathrm{H})$ was subjected to a stepwise oxidation. In each step, 
$50 \mathrm{ml}$ of $2 \% \mathrm{KMnO}_{4}-1 \% \mathrm{KOH}$ solution was added to the kerogen and the mixture was allowed to react at $60^{\circ} \mathrm{C}$. At the end of each oxidation step, $\mathrm{CO}_{2}$ generated was measured by the procedure described in the section of Experiment (1). Then, the reaction mixture was acidified with $\mathrm{HCl}$ to $\mathrm{pH} \sim 1$, filtered and washed thoroughly with distilled water. DOC in the filtrate was measured. The unreacted residue was used for the next oxidation step. Nine stepwise oxidations were performed in the total. After the 6th oxidation step, the reaction temperature was raised to $80^{\circ} \mathrm{C}$. At the end of the 9th oxidation step, the mixture was treated with sodium bisulfite and sulfuric acid to reduce the excess permanganate and manganese dioxide. The solution was filtered and the kerogen residue was dried and weighed. The filtrate obtained at each oxidation step was extracted with $n$-hexane $(50 \mathrm{ml} \times 3)$ and ethyl acetate $(50 \mathrm{ml} \times 3)$. Each extract was evaporated to dryness, weighed and methylated with $14 \%$ $\mathrm{BF}_{3}$-methanol (Metcalfe et al., 1966).

\section{Analysis of organic compounds}

The analyses of methylated organic compounds were carried out using a Shimadzu GC5A gas chromatograph equipped with a flame ionization detector. Separations were performed on a $2 \mathrm{~m} \times 3 \mathrm{~mm}$ i.d. glass column packed with $1.5 \%$ OV-17 on Chromosorb W AW DMCS (80-
100 mesh). Nitrogen was used as a carrier gas with a flow rate of $40 \mathrm{ml} \mathrm{min}$. The column temperature was programmed from $95^{\circ}$ to $280^{\circ} \mathrm{C}$ at $6^{\circ} \mathrm{Cmin}^{-1}$. The peak heights on the GC were calibrated with the standards: methyl palmitate for monocarboxylic acids, and unidentified peaks in the hexane fractions; dimethyl sebacate for $\alpha, \omega$-dicarboxylic acids, and unidentified peaks in the ethyl acetate fractions; and dimethyl phthalate for benzene carboxylic acids.

A Shimadzu-LKB 9000 gas chromatographmass spectrometer employing the same column as described above was used for identifying the organic compounds. They were identified by comparison of mass spectra and relative GCretention times with authentic standards.

\section{Results}

The amounts of various organic fractions in the lake Haruna sediment are listed in Table 1. Table 2 shows the elemental analysis of nonhydrolyzed and hydrolyzed kerogens. Upon hydrolysis with $\mathrm{HCl}$, hydrogen and nitrogen contents of kerogen $(\mathrm{Nh})$ decreased substantially. This may be due to the removal of proteinaceous materials, carbohydrates and other ralated compounds from kerogen(Nh).

Experiment (1): Figure 1 shows the

Table 1. Organic composition of Lake Haruna sediment

\begin{tabular}{lcc}
\hline Total Organic Matter* & $\begin{array}{c}\text { Concentration } \\
\text { (mg/g-dry sediment) }\end{array}$ & $\begin{array}{c}\% \text { of Total organic } \\
\text { matter* }\end{array}$ \\
\cline { 2 - 3 } Lipid & 127 & - \\
Non-hydrolyzed kerogen & & 12.5 \\
Humic acid & $29.2\left(21.4^{* *}\right)$ \\
Fulvic acid & 6.2 \\
Others*** & 1.6 \\
\hline
\end{tabular}

* Total organic matter = Organic carbon $\times 1.8$.

** Hydrolyzed kerogen.

*** Others: Calculated by subtracting the amounts of lipid, fulvic acid, humic acid and nonhydrolyzed kerogen from the total organic matter. Most of this fraction was lost during $\mathrm{HF} / \mathrm{HCl}$ treatment of the sediment sample. The fraction probably consists of carbohydrates, amino acids and other low-molecular weight compounds (ISHIWATARI, 1975). 
Table 2. Elementary composition of kerogens used for experiments

\begin{tabular}{|c|c|c|c|c|c|c|c|}
\hline & \multirow[b]{2}{*}{ Ash (\%) } & \multicolumn{4}{|c|}{ Elemental analyses* $(\%)$} & \multicolumn{2}{|c|}{ Atomic ratios } \\
\hline & & C & $\mathrm{H}$ & $\mathbf{N}$ & $\mathrm{O}^{* *}$ & $\mathrm{H} / \mathrm{C}$ & $\mathrm{N} / \mathrm{C}$ \\
\hline Non-hydrolyzed kerogen & 25.7 & 57.2 & 5.59 & 3.69 & 33.6 & 1.17 & 0.075 \\
\hline Hydrolyzed kerogen & 3.76 & 62.4 & 4.26 & 1.70 & 31.6 & 0.81 & 0.024 \\
\hline
\end{tabular}

amounts of $\mathrm{CO}_{2}$ and alkali-soluble material generated from kerogen $(\mathrm{Nh})$ vs. reaction time. Kerogen (Nh) was oxidized rapidly in the first $5 \mathrm{~min}$ and $28 \%$ of the original kerogen was decomposed to $\mathrm{CO}_{2}$. Only $7 \%$ of the original kerogen carbon remained as solid residue after $1 \mathrm{hr}$ reaction. At that time, $\mathrm{CO}_{2}$ and alkalisoluble material account for $34 \%$ and $59 \%$ of the original kerogen carbon, respectively.

Experiment (2): The time of oxidation of kerogen $(\mathrm{H})$ with $\mathrm{KMnO}_{4}$ increased from 2 min to $3 \mathrm{hr}$ with increasing the oxidation step. The increase of the oxidation time means that the relative percentage of organic compounds which are resistant to $\mathrm{KMnO}_{4}$ increases in the reaciton misture.

Approximately $95 \%$ of kerogen $(\mathrm{H})$ was degraded in the 1-5th oxidation steps. In Experiment (2), variation of the amount of acidinsoluble material was examined in the course of the oxidation of kerogen $(\mathrm{H})$. Figure 2 gives the relative amounts of $\mathrm{CO}_{2}$, acid-soluble mate-

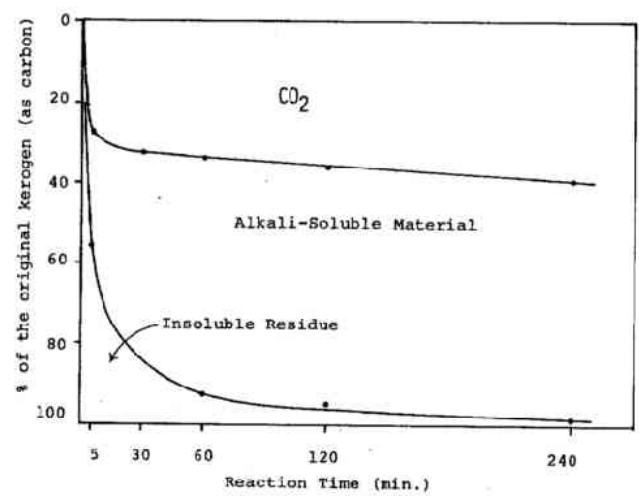

Fig. 1. Degradation process of non-hydrolyzed kerogen from Lake Haruna on $\mathrm{KMnO}_{4}$ oxidation. rial, acid-insoluble material and insoluble residue in each step of oxidation. A large amount of acid-insoluble material was produced in the first step, which accounts for $36 \%$ of the initial kerogen $(\mathrm{H})$ and decreased with proceeding the oxidation step, while $\mathrm{CO}_{2}$ and acid-soluble material increased. This result shows that the first step of the oxidation of kerogen $(\mathrm{H})$ is the formation of acid-insoluble material, which degrades into lower molecular weight compounds in the following steps.

Experiment (3): Table 3 shows the results of Experiment (3). Since the amount of hexane extract in each step of oxidation was quite low $(<1 \mathrm{mg})$, its amount is not given in Table 3 . The oxidation time of kerogen $(\mathrm{H})$ increased with the oxidation step. This trend is essentially the same as those in Experiments (1) and (2). Within $1 \mathrm{hr}$ reaction time at $60^{\circ} \mathrm{C}$ (1-4th step), $55 \%$ of the initial kerogen carbon was degraded

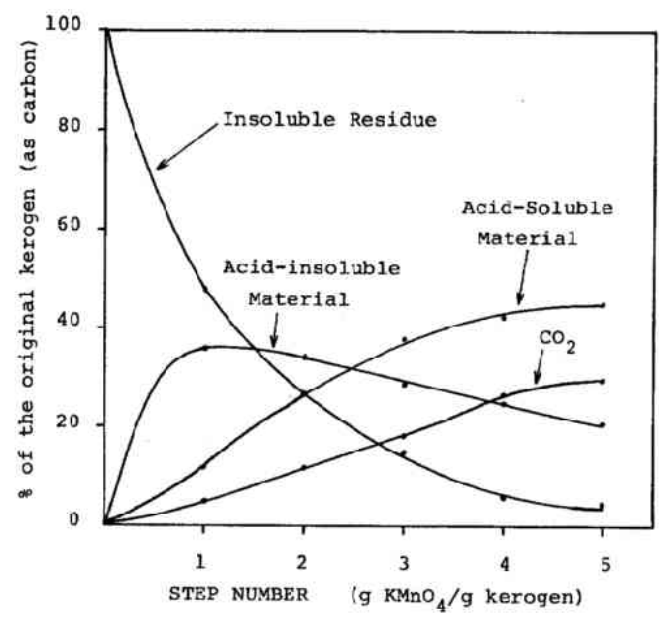

Fig. 2. Degradation process of the hydrolyzed kerogen from Lake Haruna on $\mathrm{KMnO}_{4}$ oxidation. 
Table 3. Yields of products in each oxidation step

\begin{tabular}{|c|c|c|c|c|c|c|c|c|c|c|}
\hline Step numbers & 1 & 2 & 3 & 4 & 5 & 6 & 7 & 8 & 9 & Total \\
\hline Reduction time of $\mathrm{KMnO}_{4}$ & $\begin{array}{l}60^{\circ} \mathrm{C} \\
1 \mathrm{~min}\end{array}$ & $\begin{array}{l}60^{\circ} \mathrm{C} \\
2 \mathrm{~min}\end{array}$ & $\begin{array}{l}60^{\circ} \mathrm{C} \\
5 \mathrm{~min}\end{array}$ & $\begin{array}{l}60^{\circ} \mathrm{C} \\
50 \mathrm{~min}\end{array}$ & $\begin{array}{l}60^{\circ} \mathrm{C} \\
2 \mathrm{hr} .\end{array}$ & $\begin{array}{l}60^{\circ} \mathrm{C} \\
8 \mathrm{hr} .\end{array}$ & $\begin{array}{l}80^{\circ} \mathrm{C} \\
4 \mathrm{hr} .\end{array}$ & $\begin{array}{l}80^{\circ} \mathrm{C} \\
6 \mathrm{hr} .\end{array}$ & $\begin{array}{l}80^{\circ} \mathrm{C} \\
18 \mathrm{hr}^{*}\end{array}$ & \\
\hline $\begin{array}{l}\text { Kerogen residue used in each step } \\
(\mathrm{mg}-\mathrm{C})\end{array}$ & 525 & 441 & 375 & 308 & 234 & 177 & 113 & 67.8 & 34.4 & \\
\hline $\mathrm{CO}_{2}$ generated (mg-C) & 39.1 & 34.7 & 32.2 & 42.1 & 35.7 & 47.1 & $\begin{array}{r}34.0 \\
0.5\end{array}$ & 28.4 & & 321 \\
\hline $\begin{array}{l}\text { Acid-soluble products (mg-C) } \\
\text { Ethyl acetate extracts (mg-C) }\end{array}$ & $\begin{array}{r}45.2 \\
7.4\end{array}$ & $\begin{array}{r}31.5 \\
5.8\end{array}$ & $\begin{array}{r}34.1 \\
9.2\end{array}$ & $\begin{array}{l}32.4 \\
12.7\end{array}$ & $\begin{array}{r}21.4 \\
9.8\end{array}$ & $\begin{array}{r}18.6 \\
7.5\end{array}$ & 9.5 & $\begin{array}{r}5.0 \\
3.1^{* * * *}\end{array}$ & $\begin{array}{l}2.2 \\
\text { tr.*** }\end{array}$ & $\begin{array}{r}200 \\
55.5\end{array}$ \\
\hline \multicolumn{11}{|l|}{$\begin{array}{l}\text { Total organic acids appeared on GC } \\
(\mu \mathrm{g})\end{array}$} \\
\hline Hexane fraction & 23.7 & n.a.** & 71.4 & n.a. & 186 & 33.4 & & 0.6 & tr. & 355 \\
\hline Ethyl acetate fraction & 800 & 715 & 2930 & 6320 & 6080 & 1920 & 61 & & 9.7 & 19400 \\
\hline \multicolumn{11}{|l|}{ Organic acids identified $(\mu \mathrm{g})$} \\
\hline $\begin{array}{l}\text { Aliphatic monocarboxylic acids } \\
\left(\mathrm{C}_{8}-\mathrm{C}_{18}\right)\end{array}$ & 8.76 & n.a. & 16.6 & n.a. & 67.0 & 18.1 & & 4.2 & tr. & 125 \\
\hline $\begin{array}{l}\text { Aliphatic dicarboxylic acids } \\
\left(\mathrm{C}_{5}-\mathrm{C}_{16}\right)\end{array}$ & 497 & 520 & 2190 & 4860 & 5400 & 1660 & 46 & & 0.9 & 15600 \\
\hline $\begin{array}{l}\text { Benzene carboxylic acids } \\
\text { (mono, di and tri-) }\end{array}$ & 118 & 125 & 511 & 1140 & 610 & 223 & 11 & & 6.5 & 2840 \\
\hline
\end{tabular}

${ }^{*} \mathrm{KMnO}_{4}$ was not completely reduced. ${ }^{* *}$ n.a. $=$ not analyzed.

trace amount.

***** step $7+$ step 8

into $\mathrm{CO}_{2}$ and acid-soluble material. The $\mathrm{CO}_{2}$ accounts for approximately $28 \%$ of the initial kerogen carbon. The higher (at $80^{\circ} \mathrm{C}$ ) the oxidation temperature, the yield of acid-soluble material became lower and the weight ratio of $\mathrm{CO}_{2}$ to acid-soluble material increased from 0.9 (step 1) to 12.5 (step 9). This fact shows that the acid-soluble material which was once formed by the oxidation of kerogen $(\mathrm{H})$ was decomposed further into $\mathrm{CO}_{2}$ under such drastic conditions. Insoluble residue remained after the last (the 9th) oxidation step was $4.7 \mathrm{mg}$ as carbon, and the amounts of $\mathrm{CO}_{2}$ and acid-soluble material were 321 and $200 \mathrm{mg}$ as carbon, respectively. Therefore, the total amounts of the organic carbon recovered was $525 \mathrm{mg}$, which is $87 \%$ of the initial kerogen carbon. The amount of the ethyl acetate extracts was $5.6 \%$ of the initial kerogen $(\mathrm{H})$.

Figure 3 gives examples of gas chromatograms of $n$-hexane and ethyl acetate extracts obtained in steps 1,5 and $7+8$. Aliphatic normal monocarboxylic acids $\left(\mathrm{C}_{8}-\mathrm{C}_{18}\right)$ and aliphatic normal $\alpha, \omega$-dicarboxylic acids $\left(\mathrm{C}_{13}-\mathrm{C}_{16}\right)$ were identified in the n-hexane extracts. The oxidation products in the ethyl acetate extracts were aliphatic normal $\alpha, \omega$-dicarboxylic acids $\left(\mathrm{C}_{5}-\mathrm{C}_{12}\right)$ and benzene carboxylic acids (benzoic acid, phthalic acid and trimellitic acid). The com- pounds mentioned above were identified on the basis of their mass spectra and GC retention times. Unidentified peaks were also observed on the gas chromatograms.

The amounts of aliphatic mono- and dicarboxylic acids and benzene carboxylic acids in each step are given in Table 3. "Total organic acids" in Table 3 means the sum of the identified and unidentified compounds appeared on a gas chromatogram of the oxidation products. Most "total organic acids" are found in an ethyl acetate extract, the former accounting for 11$62 \%$ of the latter. A dominant component of "total organic acids" is aliphatic normal dicarboxylic acids ( $79 \%$ on an average); benzene carboxylic acids, aliphatic normal monocarboxylic acids and unidentified compounds amount to $14.4,0.6$ and $6.0 \%$ (on an average), respectively.

\section{Discussion}

This paper is the first detailed study of the oxidation process of young kerogen. All oxidation products including $\mathrm{CO}_{2}$ were determined quantitatively.

A marked feature of the behavior of kerogen on oxidation is its very fast oxidation, that is, at the oxidation within $1 \mathrm{hr}$ at $60^{\circ} \mathrm{C}$, kerogen 
was almost converted into $\mathrm{CO}_{2}$ and alkali-soluble material (93 and $94 \%$ for Experiments (1) and (2), respectively). According to our unpublished results on fossil kerogens (Green River shale, Tasmanian tasmanite and Australian torbanite), only $5-31 \%$ of the kerogens changed into $\mathrm{CO}_{2}$ and alkali-soluble material by $\mathrm{KMnO}_{4}$ oxidation in the same $\left(60^{\circ} \mathrm{C}, 1 \mathrm{hr}\right)$ condition. Oxygen contents of those fossil kerogens are rather low (4.3-13.8\%: MACHIHARA and IshIWATARI, un-

Hexane Extracts
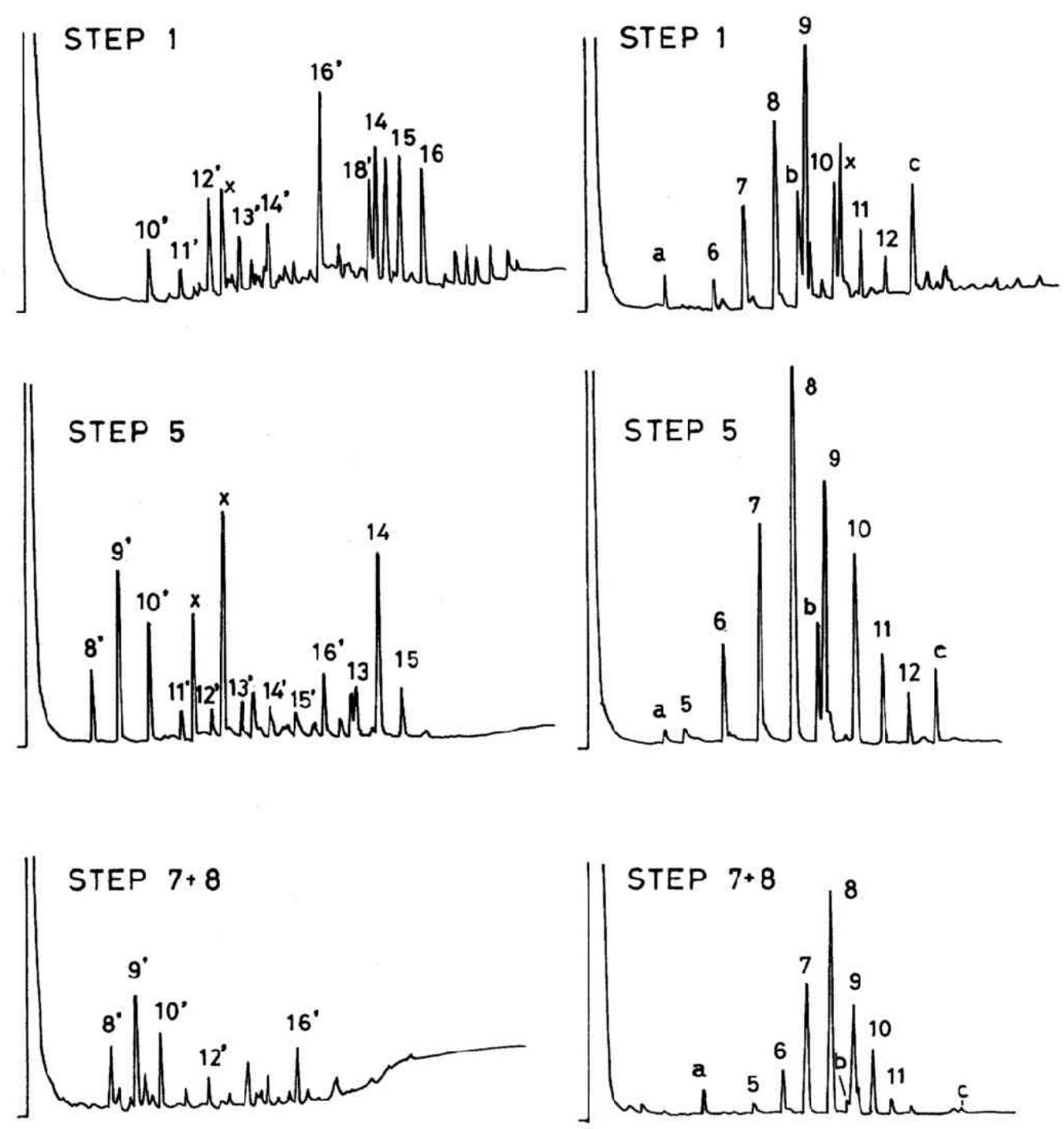

Fig. 3. Gas chromatograms of the n-hexane and ethyl acetate extracts in steps 1, 5, and 7+8. The carbon numbers of the normal $\alpha, \omega$-dicarboxylic acids are indicated by the arabic numerals and normal monocarboxylic acids are indicated by the primed arabic numerals. The letters designate the following compounds: (a) Benzoic acid. (b) Phthalic acid. (c) Trimellitic acid. (x) Unidentified peak. GC conditions are as stated in the text (except for steps $7+8$ ). The oxidation products in steps $7+8$ were analyzed as propyl esters. The column temperature was programmed from 100 to $280^{\circ} \mathrm{C}$ at $8^{\circ} \mathrm{C} \mathrm{min}^{-1}$. 
published). Therefore, such a high oxidation rate of the young kerogen may be closely associated with its high oxygen content (31.6$33.6 \%$ ), since chemical bonds adjacent to oxygen are considered to be very weak to the oxidizing reagent. This is consistent with the work of ERDMAN and RAMSEY (1961), who reported that $\mathrm{KMnO}_{4}$ oxidation rates at $78^{\circ} \mathrm{C}$ of various bituminous substances from coals, oil shales and other natural bitumens showed a correlation with their oxygen contents.

There is a great difference in the degradation behavior of kerogen into acid-insoluble material between young kerogen and fossil kerogen. In the case of the Haruna kerogen, a large amount of acid-insoluble material (36\% of the initial kerogen) was formed at the initial step of oxidation. On the other hand, according to the stepwise oxidation experiment of a fossil kerogen (Green River shale) conducted by YounG and YEN (1977), it produced only a small amount of acid-insoluble material $(1.2 \%$ of the initial kerogen) at the early (1-2) steps of oxidation; at the later (7-9) oxidation steps, a relatively large amount (about $30 \%$ of the initial kerogen) of acid-insoluble material was formed.

This fact for the young kerogen may also be closely related with the presence of a large amount of oxygen-containing functional groups

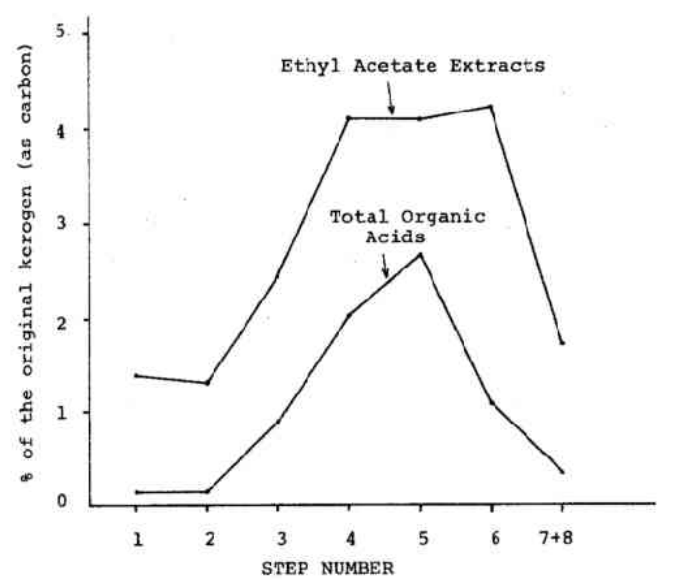

Fig. 4. Yields of ethyl acetate extracts and total organic acids on gas chromatograms in each step. in it. As shown in Fig. 4, at the early steps of oxidation in Experiment (3), the amounts of "total organic acids" and the ethyl acetate extracts are small as compared with those at later steps. This fact shows that $\mathrm{KMnO}_{4}$ in steps 1 and 2 was consumed to decompose relatively weak chemical bonds such as $\mathrm{C}-\mathrm{O}-\mathrm{C}$ and $\mathrm{C}-\mathrm{C}$ adjacent to oxygen in the kerogen and then, in the steps later than 3 , its polymethylene chains began to be attacked in a larger extent. In the case of the fossil kerogen, on the other hand, aliphatic-type cluster connected by polymethylene chains has only a small amount of oxygen, and they are quite resistant to $\mathrm{KMnO}_{4}$, as reported by KRSMANOvic et al. (1978) for Aleksinac shale kerogen. This may be the reason why acid-insoluble material is formed mostly at the later stages of oxidation.

The main oxidation products of the young kerogen are aliphatic normal- $\alpha, \omega$-dicarboxylic acids $\left(\mathrm{C}_{5}-\mathrm{C}_{16}\right)$; benzene carboxylic acids and normal monocarboxylic acids $\left(\mathrm{C}_{8}-\mathrm{C}_{18}\right)$ are minor constituents. Interestingly, the relative ratio of three types of those compounds in various oxidation steps is quite similar (Fig. 5). This fact suggests that the components which produce those compounds are homogeneous in the kerogen in terms of relative ratio. The oxidation products for the young kerogen is some-

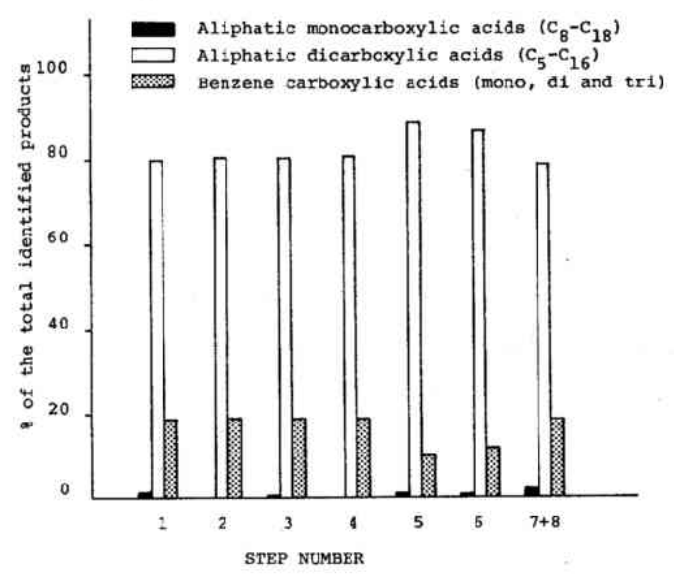

Fig. 5. Composition of aliphatic monocarboxylic acids, aliphatic dicarboxylic acids and benzene carboxylic acids in each oxidation step. 
what different from those for the young kerogen from algal mats (PHILP and YANG, 1977). In the case of algal mats-kerogen, the oxidation products by the reflux with $5 \% \mathrm{KMnO}_{4}$ for $4 \mathrm{hr}$ are dominated by the normal carboxylic acids in the range $\mathrm{C}_{11}-\mathrm{C}_{31}\left(\max\right.$. at $\left.\mathrm{C}_{16}\right)$ with minor amounts of $\alpha, \omega$-dicarboxylic acids $\left(\mathrm{C}_{9}\right.$ $\mathrm{C}_{16}$ : $\max$. at $\mathrm{C}_{11}$ ). The presence of benzene carboxylic acids was not reported. Since organic matter from soils surrounding the lake may contribute to our kerogen in some extents, no detection of benzene carboxylic acids in the oxidation products of the algal mats-kerogen is quite reasonable. The similar types of organic acids to those found in this study (i.e. normal monocarboxylic acids and $\alpha, \omega$-dicarboxylic acids) have been found in the oxidation products of fossil kerogens (DJURICIC et al., 1971, 1972; SimoneIt and BurLINGAME, 1973; VITOROvic et al., 1974; Young and YEN, 1977); aromatic acids have been also found in various amounts depending on samples. This fact shows that the young kerogen resembles the fossil kerogens in terms of the composition of the oxidation products.

Total amounts of acid-soluble material, organic solvent-extractable acids and $\alpha, \omega$-dicarboxylic acids plus monocarboxylic acids account for $20.0,5.6$ and $1.6 \%$ of the original young kerogen, respectively. The yields of organic solvent-extractable acids obtained from the stepwise oxidation of the Green River shale kerogen are $27.1 \%\left(2 \% \mathrm{KMnO}_{4}\right.$ in $1 \% \mathrm{KOH}$ at $75^{\circ} \mathrm{C}$, methanol and ether extracts: YouNG and YEN, $1977)$ and $22.3 \%\left(1.25 \% \mathrm{KMnO}_{4}\right.$ in $1.6 \% \mathrm{KOH}$ at $80^{\circ} \mathrm{C}$, methylene chloride and ether extracts: DJURICIC et al., 1971) on the basis of the weight of the original kerogen. Although the oxidation condition for the fossil kerogen is more drastic than that for the young kerogen, the yield of extractable acids for the former is much higher than for the latter. This would show that the concentration of polymethylene chains in the fossil kerogen, which give rise to aliphatic dicarboxylic acids as main products, is much higher than that in the young kerogen. This is consistent with the data of elementary com-
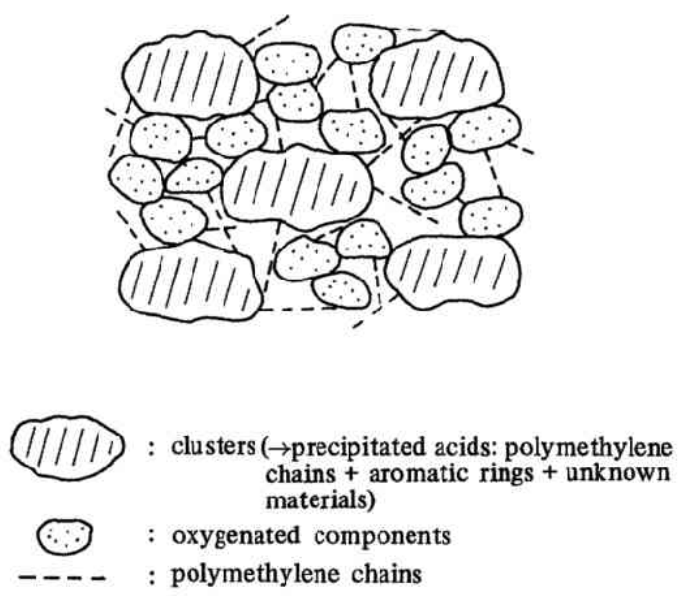

Fig. 6. Hypothetical structure of the young kerogen from Lake Haruna.

position of the kerogens, that is, atomic $\mathrm{H} / \mathrm{C}$ ratios are 0.81 for the young kerogen and 1.551.59 for the fossil kerogen, respectively.

A hypothetical structure of the young kerogen may be deduced from the results mentioned above, as shown in Fig. 6. The kerogen has a large percentage of oxygen-containing components, which are probably melanoidinlike material (condensation products of carbohydrates and amino acids) (HoERING, 1974). The oxygen-containing components connect clusters and are readily decomposed to $\mathrm{CO}_{2}$ on oxidation. The clusters may consist of polymethylene chains, aromatic rings and other materials, and change into acid-insoluble material on oxidation, which, on further oxidation, may produce aliphatic mono- and dicarboxylic acids, benzene carboxylic acids and other unidentified compounds. A series of aliphatic mono- and dicarboxylic acids $\left(\mathrm{C}_{5}-\mathrm{C}_{18}\right)$ which come easily from the kerogen upon oxidation, may be derived from polymethylene chains of various lengths which are combined with clusters or oxygenated components. Since the atomic $\mathrm{H} / \mathrm{C}$ ratio of the young kerogen is relatively low (0.81) and the yield of aliphatic acids on oxidation is also low $(1.6 \%$ of the initial kerogen), the overall concentration of polymethylene chains in the kerogen may be quite 
small (less than 10\%?).

\section{CONCLUSION}

The present study of the oxidative degradation of a young kerogen from Lake Haruna revealed the following points:

(1) The young kerogen is more susceptible to oxidation than fossil kerogens. More than $90 \%$ of the young kerogen is easily degraded under the mild condition $\left(2 \% \mathrm{KMnO}_{4}, 60^{\circ} \mathrm{C}\right.$ for $\left.1 \mathrm{hr}\right)$.

(2) A relatively large amount of $\mathrm{CO}_{2}$ is generated at the early steps of the oxidation (18-28\% of the original kerogen).

(3) The formation of the acid-insoluble material at the initial step of oxidation is another feature observed for the young kerogen.

(4) The features mentioned above may be closely associated with the presence of the large amount of oxygen (that is, oxygen-containing functional groups) in the kerogen.

(5) The main oxidation products determined by $\mathrm{GC}$ are aliphatic normal $\alpha, \omega$-dicarboxylic acids. Aromatic acids and aliphatic monocarboxylic acids were also detected in minor amounts. The yield of aliphatic mono- and dicarboxylic acids was $1.6 \%$ of the original kerogen.

(6) A hypothetical structure of the young kerogen was deduced from the results mentioned above.

Acknowledgement-This work financially supported by the Toyota Foundation (Grant No. 79-1-161).

\section{REFERENCES}

Burlingame, A. L. and Simoneit, B. R. (1968) Isoprenoid fatty acids isolated from the kerogen matrix of the Green River Formation (Eocene). Science 160, 531-533.

BURLINGAME, A. L. and SIMONEIT, B. R. (1969) High resolution mass spectrometry of Green River Formation kerogen oxidations. Nature 222, 741747.

Burlingame, A. L., HaUg, P. A., SChNOES, H.K. and SIMONEIT, B. R. (1969) Fatty acids derived from the Green River Formation oil shale by extractions and oxidations - A review. in Advances in Organic
Geochemistry 1968, P. A. SCHENK and I. HAVENAAR (Eds.) Permagon Press, Oxford. 85-129.

DJURICIC, M. V., MURPHY, R. C., VITOROVIC, D. and BIEMANN, K. (1971) Organic acids obtained by alkaline permanganate oxidation of kerogen from the Green River (Colorado) shale. Geochem. Cosmochim. Acta 35, 1201-1207.

DJuricic, M. V., Vitorovic, D., ANDRESEN, B. D., HERTZ, H. S., MURPhY, R. C., PRETI, G. and BIEMANN, K. (1972) Acids obtained by oxidation of kerogens of ancient sediments of different geographic origin. in Advances in Organic Geochemistry 1971, H. R. VON GAERTNER and H. WEHNER (Eds.) Permagon Press, Oxford. 305-321.

ERdmaN, J. G. and RAMSEY, V. G. (1961) Rates of oxidation of petroleum asphaltenes and other bitumens by alkaline permanganate. Geochim. Cosmochim. Acta 25, 175-188.

HOERING, T. C. (1973) The benzene-soluble organic matter, humic acids, and insoluble organic matter in a core from the Cariaco Trench. Carnegie Inst. Washington Yearb. 71, 585-592.

HOERING, T. C. (1974) A comparison of melanoidin and humic acid. Carnegie Inst. Washington Yearb. 72, 682-690.

ISHIWATARI, R. (1975) Transformation of sedimentary humic acids, facts and speculaions. in Humic Substances. Their structure and function in the biosphere, D. Povoledo and H. L. Bolterman (Eds) Pudoc. Wageningen, 109-121.

ISHIWATARI, R., OGURA, K. and HORIE, S. (1980) Organic geochemistry of a lacustrine sediment (Lake Haruna, Japan). Chemical Geology 29, 261-280.

KRSMANOVIC, V. D., ERCEGOVAC, M. and Vitorovic, D. (1978) Parallel micropetrographic and chemical studies of the solid degradation products from stepwise alkalin epermanganate oxidation of a kerogen concentrate. Organic Geochemistry 1, 85-88.

MENZEL, D. W. and VACCARO, R. F. (1964) The measurement of dissolved organic and particulate carbon in seawater. Limnol. Oceanogr. 9, 138-142.

Metcalfe, L. D., SChmitz, A. A. and PelKa, J. R. (1966) Rapid preparation of fatty acid esters fro lipids for gas chromatographic analysis. Anal. Chem. 38, 514-515.

PhilP, R. P. and Calvin, M. (1977) Kerogeneous material in Recent algal mats at Laguna Mormona, Baja California. in Advances in Organic Geochemistry 1975 , R. CAMPOS and J. GoNI (Eds.) Enadimsa, Madrid. 735-752.

PHILP, R. P. and YANG, E. (1977) Alkaline potassium permanganate degradation of insoluble organic residues (kerogen) isolated from recently-deposited algal mats. Energy Sources 3, 149-161.

PhIlP, R. P., CalVin, M., Brown, S. and YANG, E. 
(1978) Organic geochemical studies on kerogen precursors in recently deposited algal mats and oozes. Chemical Geology 22, 207-231.

RIFFALDI, R. and SCHNITZER, M. (1973) Effects of $6 \mathrm{~N} \mathrm{HCl}$ hydrolysis on the analytical characteristics and chemical structure of humic acids. Soil Science $115,349-356$.

SimoneIT, B. R. and Burlingame, A. L. (1973) Carboxylic acids derived from Tasmanian tasmanite by extractions and kerogen oxidations. Geochim. Cosmochim. Acta 37, 595-610.

SimoneIT, B. R. and BuRLINGAME, A. L. (1974)

Ketones derived from the oxidative degradation of
Green River Formation oil shale kerogen. in Advances in Organic Geochemistry 1973, B. TissoT and F. BIENNER (Eds.) Technip, Paris. 191-202.

Vitorovic, D., DJuRICIC, M. V. and ILIC, B. (1974) New structural information obtained by stepwise oxidation of kerogen from the Aleksinac (Yugoslavia) shale. in Advances in Organic Geochemistry 1973, B. TissoT and F. BIENNER (Eds.) Tecnip, Paris. 179-189.

YounG, D. K. and YEN, T. F. (1977) The nature of straight-chain aliphatic structures in Green River kerogen. Geochim. Cosmochim. Acta 41, 14111417. 